\title{
Detection of Carbamazepine Level among Patients Visiting Psychiatric and Pediatric Services of a Tertiary Hospital in Eastern Nepal
}

\author{
- Dipesh Raj Panday¹ • Gajendra Prasad Rauniar' • Dilli Sher Rai ${ }^{1}$ Karishma Rajbhandari Panday ${ }^{2}$ \\ - Madhur Basnet ${ }^{3} \bullet$ Shyam Prasad Kafle ${ }^{4}$
}

Submitted 4 February 2021

\section{Dipesh Raj Panday}

dipesh.pandey@bpkihs.edu

iD https://orcid.org/0000-0002-7625-3835

${ }^{1}$ Department of Clinical Pharmacology and Therapeutics

2 Department of Basic and Clinical Physiology

${ }^{3}$ Department of Psychiatry

${ }^{4}$ Department of Pediatrics and Adolescent Medicine,

B. P. Koirala Institute of Health Sciences, Dharan, Nepal

\section{Citation}

“Panday D, Rauniar G, Rai D, Rajbhandari Panday K, Basnet M, Kafle SP. Detection of carbamazepine level among patients visiting psychiatric and paediatric services of tertiary hospital in eastern Nepal. JBPKIHS. 2021;4(1):15-19.

doi https://doi.org/10.3126/jbpkihs.v4i1.36993

\section{(c) (1) $\otimes(\Theta$}

This work is licensed under a Creative Commons AttributionNonCommercial 4.0 International License.
Accepted 30 May 2021

Published 30 June 2021

Background: Carbamazepine plasma level is directly related to dose, therapeutic effect, and toxicity. We aimed to observe its plasma level and relationship with dose among psychiatric and pediatric patients.

Methods: This observational study was performed in the Therapeutic Drug Monitoring Laboratory of a university hospital for a period of I.5 years. Twentysix consenting patients visiting either psychiatric or pediatric service and taking carbamazepine same dose for $>8$ days (i.e. $>6$ half-lives) were enrolled. The primary outcome was plasma carbamazepine level as determined by a High-Performance Liquid Chromatography machine. The secondary outcome included its correlation with dose assessed by the Spearman rho's correlation coefficient.

Results: The mean dose received by the patients was $13.31 \pm 5.39 \mathrm{mg} / \mathrm{kg} / \mathrm{day}$ in pediatrics and $8.33 \pm 2.29 \mathrm{mg} / \mathrm{kg} /$ day in psychiatry. The plasma levels [median (IQR)] were I0.0I $(6.27,13.35) \mathrm{mg} / \mathrm{L}$ and $10.53(5.17,15.19) \mathrm{mg} / \mathrm{L}$ respectively in pediatric and psychiatric patients. Thirteen patients $(50 \%)$ had therapeutic, 10 (36.46\%) had above therapeutic, and 3 (1 I.54\%) had subtherapeutic plasma level. Neurocysticercosis $(23.1 \%)$ in pediatrics and partial seizure $(69 \%)$ in psychiatry were the most common diagnosis. Symptom-control was achieved in $19(73.1 \%)$ patients. The plasma carbamazepine level did not correlate with dose either in pediatric patients $(p=0.42)$ or in psychiatry patients $(p=0.63)$. Conclusion: The plasma carbamazepine levels [median (IQR)] in pediatric and psychiatric patients were $10.01(6.27,13.35) \mathrm{mg} / \mathrm{L}$ and $10.53(5.17,15.19)$ $\mathrm{mg} / \mathrm{L}$ respectively. The plasma level was normal in half of the recruited patients and did not correlate with dose.

Keywords: Carbamazepine, High performance liquid chromatography, Plasma level, Toxicity

\section{Declarations}

Ethics approval and consent to participate: Ethical approval obtained from the Institutional Review Committee, B.P. Koirala Institute of Health Sciences (Ref. No.- IRC/ 0747/ 016). Informed consent was taken from the adult patients and parents of pediatric patients before enrollment in the study.

Consent for publication: Not applicable

Availability of data and materials: The datasets used and/ or analyzed during the current study are available from the corresponding author on reasonable request. All relevant data are within the manuscript and the supplementary file.

Competing interest: None

Funding: Institute's Research Grant was obtained to meet expenses while running research machine (HPLC).
Authors' contributions: DRP, GPR: Concept, design, definition of intellectual content, literature search, data acquisition, statistical analysis, manuscript preparation, manuscript editing and review. DSR, MB, SK, KRP: Data acquisition, definition of intellectual content, literature search, statistical analysis, manuscript editing and review. All authors have read and approved the final manuscript.

Acknowledgement:We acknowledge Mr. Bhupendra K. Yadav, the technician in the Department of Clinical Pharmacology and Therapeutics, for helping in technical aspect of HPLC machine. We also thank all the patients and their families for the enthusiastic participation. 
$\mathrm{C}$ arbamazepine is an antiepileptic drug that has been successfully used in a variety of neurological and psychiatric disorders [1]. As monotherapy, it is used in partial seizures, grand-mal seizures, affective disorders, and behavioral problems [2-4]. It is also used in combination with other anti-epileptics to treat a variety of conditions [5]. It is preferred because it is effective and has fewer long-term metabolic and cognitive adverse effects [6-8].

Plasma carbamazepine level is directly related to its dose, therapeutic effect, and toxicity. It is affected by several factors such as drug interaction, food, or the pharmacokinetic profile of patients $[9,10]$. Therefore, the primary objective of this study was to observe the plasma carbamazepine level in two different sets of population (pediatric and psychiatric). The secondary objective was to correlate its plasma level with the dose administered.

\section{METHODS}

$\mathrm{T}$ This descriptive observational study was carried out in the Therapeutic Drug Monitoring (TDM) Laboratory, High Performance Liquid Chromatography (HPLC) room of the Department of Clinical Pharmacology and Therapeutics of the university hospital of B. P. Koirala Institute of Health Sciences (BPKIHS). Ethical approval was obtained from the Institutional Review Committee, BPKIHS. Enrollment of patients started on January 2017 with the last case being enrolled on April 2018 after obtaining informed consent from the adult patients and parents of pediatric patients. The confidentiality and anonymity of the participants were strictly maintained.

We enrolled patients visiting either psychiatric or pediatric service taking carbamazepine same dose for $>$ 8 days (i.e. $>6$ half-lives) for any indication. However, patients with any diagnosed coagulation disorder like hemophilia, which may pose a risk of excessive bleeding during blood sampling were excluded. A convenience sampling technique was used to recruit the patients. Based on previously reported two different values of carbamazepine levels (10 $\pm 5 \mathrm{mg} / \mathrm{L}$, and $7 \mathrm{mg} / \mathrm{L}$ ), a sample size of 22 was estimated at $95 \%$ confidence interval and $80 \%$ power [11-13] to reduce the different possible biases, 20\% more sample size was considered and 26 patients were enrolled.

A detailed description of the procedure of carbamazepine detection with HPLC in TDM Lab is given as a supplementary file. The primary outcome was carbamazepine plasma level as determined by an HPLC machine. Secondary outcomes included its correlation with dose as assessed by the Spearman rho's correlation coefficient.

Relevant data regarding the patient's profile (demographic and anthropometric), drug dose, and plasma level of the drug were entered in a semi-structured proforma. Microsoft Excel (Microsoft Office 2016) was used for data entry and analysis were done with Statistical Package for the Social Sciences version 11.5 (SPSS Inc; Chicago, IL, USA). The Spearman rho's correlation was used to assess the association between the dose and plasma level. A p-value of $<0.05$ was considered significant. The results were described as percentage (\%), mean, standard deviation (SD), median, and interquartile range (IQR).

\section{RESULTS}

ltogether 13 patients from pediatrics and 13 from psychiatry were enrolled (Table 1). There was no missing data. The age of the patients (mean \pm SD) was $11.23 \pm 3.7$ years in pediatrics and $34.2 \pm 14.3$ years in psychiatry. One patient from psychiatry was in the pediatric age group (14 years). The male to female ratio was 1.6:1 in both pediatrics and psychiatry.

With the use of the drug, symptom-control was achieved in 19 (73.07\%) patients. Sustained release tablets of carbamazepine (Zeptal $®$, Sun Pharmaceutical Industries Ltd), were prescribed in 14 (53.8\%) patients. In 24 (92.3\%) patients, carbamazepine was prescribed in two divided doses.

Table 1. Anthropometric variables of the patients. Values are expressed as mean \pm SD.

\begin{tabular}{lll}
\hline & Pediatrics $(\mathrm{n}=\mathrm{I3})$ & Psychiatry $(\mathrm{n}=\mathrm{I3})$ \\
\hline Height $(\mathrm{m})$ & $\mathrm{I} .31 \pm 0.26$ & $1.56 \pm 0.06$ \\
Weight $(\mathrm{Kg})$ & $34.38 \pm 13.36$ & $59.0 \pm 12.46$ \\
BMI $\left(\mathrm{Kg} / \mathrm{m}^{2}\right)$ & $19.47 \pm 2.52$ & $24.17 \pm 4.47$ \\
\hline
\end{tabular}

BMl: Body Mass Index

In psychiatry, 9 (69\%) patients had focal/ partial seizure with secondary generalization as the most common diagnosis, whereas in pediatrics, 3 (23.1\%) patients took the drug for neurocysticercosis with seizure (Fig. 1, 2).

Though apparently lower dose was prescribed in pediatrics $(423.08 \pm 200.64 \mathrm{mg} /$ day $)$ than in psychiatry (484.62 $\pm 157.30 \mathrm{mg} /$ day), when body weight was 
Figure 1: Diagnosis in pediatric patients taking carbamazepine. NCC: Neurocysticercosis, GTCS*: Generalized tonic clonic seizure secondary to pyogenic meningitis/ meningoencephalitis, SG: secondary generalization

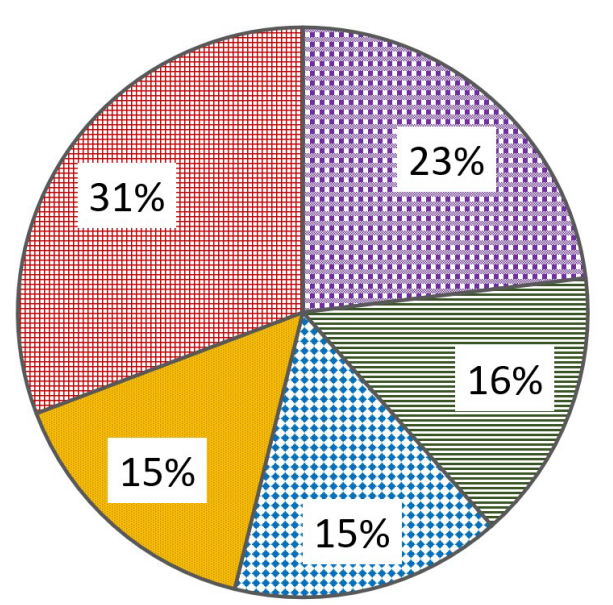

圈NCC with seizure

目Rolandic epilepsy

国GTCS*

$\square$ Focal/ partial seizure with SG

国Others considered, drug dose per kg body weight prescribed in pediatrics $(13.31 \pm 5.39 \mathrm{mg} / \mathrm{kg} /$ day $)$ was significantly higher than that in psychiatry $(8.33 \pm 2.29 \mathrm{mg} / \mathrm{kg} /$ day $)$ $(\mathrm{p}<0.05)$.

The plasma level of carbamazepine [median (IQR)] was $10.27(6.11,13.58) \mathrm{mg} / \mathrm{L}$ in all patients, $10.01(6.27,13.35) \mathrm{mg} / \mathrm{L}$ in pediatrics and $10.53(5.17$, 15.19) $\mathrm{mg} / \mathrm{L}$ in psychiatry. Thirteen patients had therapeutic plasma level based on the institute's normal reference laboratory value of 4-12 mg/L (Table 2).

Table 2: Therapeutic categorization of plasma level based on lab reference 4-12 mg/L. Values are expressed as $\mathrm{n}(\%)$.

\begin{tabular}{llll}
\hline & Subtherapeutic & Therapeutic & $\begin{array}{l}\text { Above } \\
\text { Therapeutic }\end{array}$ \\
\hline $\begin{array}{l}\text { Psychiatry } \\
(\mathrm{n}=13)\end{array}$ & $2(15.4)$ & $5(38.5)$ & $6(46.1)$ \\
$\begin{array}{l}\text { Pediatrics } \\
(\mathrm{n}=13)\end{array}$ & $1(7.7)$ & $8(61.5)$ & $4(30.8)$ \\
$\begin{array}{l}\text { Total } \\
(\mathrm{n}=26)\end{array}$ & $3(11.5)$ & $13(50.0)$ & $10(38.5)$ \\
\hline
\end{tabular}

No correlation was found between drug dose with plasma level in either pediatrics or psychiatry (Table 3).Clinical toxicity was observed in four patients among whom three patients had plasma level of the drug above the therapeutic range (Table 4).
Table 3: Correlation of carbamazepine plasma level with dose

\begin{tabular}{lll}
\hline & $\begin{array}{l}\text { Correlation coefficient } \\
\text { (Spearman's rho) }\end{array}$ & $p$-value \\
\hline Dose in $\mathrm{mg} / \mathrm{kg} /$ day & & \\
\hline Pediatrics & 0.07 & 0.82 \\
Psychiatry & 0.14 & 0.65 \\
Total & 0.01 & 0.95 \\
\hline Dose in mg/day & & \\
\hline Pediatrics & 0.24 & 0.42 \\
Psychiatry & 0.14 & 0.64 \\
Total & 0.02 & 0.93 \\
\hline
\end{tabular}

\section{DISCUSSION}

ur laboratory reference range of carbamazepine levels for patients of any age or pathology is 4-12 mg/L. A wide variety of reference levels ranging from $5-10 \mathrm{mg} / \mathrm{L}$ to $6-8 \mathrm{mg} / \mathrm{L}$ have been described in the literature and the peak level is recommended not to exceed 10 to $12 \mathrm{mg} / \mathrm{L}$ to avoid adverse effects [12, 14].

A study done in 241 participants in the National Public Health Laboratory, Kathmandu, Nepal in 2007 with the same reference range as ours (4-12 $\mathrm{mg} / \mathrm{L}$ ) showed that $4.9 \%$ of participants (vs $38.5 \%$ in ours)

Table 4: Profile of patients with clinical toxicity of carbamazepine

\begin{tabular}{|c|c|c|c|c|c|c|}
\hline S. No. & Age/ Sex & Clinical diagnosis & Dose $(\mathrm{mg} / \mathrm{kg} /$ day $)$ & Other drug & $\begin{array}{l}\text { Plasma level } \\
(\mathrm{mg} / \mathrm{L})\end{array}$ & Symptoms \\
\hline I & $\mid 7 / M$ & TLE with SG & 12.0 & None & 239.34 & $\begin{array}{l}\text { Dizziness, sedation, hypo- } \\
\text { tension }\end{array}$ \\
\hline 2 & $4 I / M$ & $\begin{array}{l}\text { Focal/ partial Seizure } \\
\text { with SG }\end{array}$ & 9.26 & None & $\mid 4.4 \mathrm{I}$ & Dizziness \\
\hline 3 & $\mathrm{II} / \mathrm{M}$ & Rolandic epilepsy & 16.0 & None & 3.80 & Dizziness, sedation, diplopia \\
\hline 4 & $8 / \mathrm{F}$ & NCC with seizure & 5.88 & Sodium valproate & 13.60 & Dizziness, sedation \\
\hline
\end{tabular}

TLE:Temporal lobe epilepsy, SG: secondary generalization, NCC: Neurocysticercosis 
Figure 2: Diagnosis in psychiatric patients taking carbamazepine. SG: secondary generalization, GTCS: generalized tonic clonic seizure.

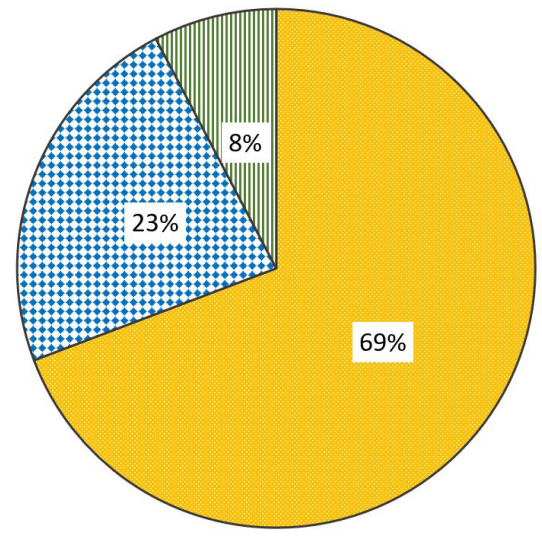

口Focal/Partial Seizure with SG 回GTCS

mBipolar affective disorder had above therapeutic drug level, $79.3 \%$ (vs $50 \%$ in ours) had therapeutic drug level and $15.8 \%$ (vs $11.54 \%$ in ours) had subtherapeutic drug level [15].

Several authors claim that the plasma level of carbamazepine is directly correlated with dose, therapeutic effect, and side effects $[16,17]$. Our study could not reveal any correlation between the dose administered and plasma level. Free fraction carbamazepine shows considerable inter-individual variability, especially in the presence of associated disease and multiplicity of pharmacokinetic and pharmacogenetic variables [12, 18]. Non-linear relationship between the dose and the plasma concentration of carbamazepine even within the range of therapeutic doses has also been reported [19]. Especially among the pediatric age group, the correlation between carbamazepine dose and plasma level is difficult for various reasons [20]. These findings highlight the need for individualized therapy [21]. Carbamazepine plasma level determinations can be used for the prediction of the total effect of carbamazepine treatment including neurologic and cardiovascular features [22].

In our study, there were four cases of clinical toxicity. One case had a plasma level of $239.34 \mathrm{mg} / \mathrm{L}$ and believed to be an outlier. We had calibrated the machine (HPLC) using first order kinetics. At this gigantic level, metabolism mechanics get saturated, and zero order kinetics is followed [23], therefore we cannot guarantee the correct level shown by the machine. While one patient on carbamazepine monotherapy manifested toxicity despite his plasma level was below therapeutic (3.8 $\mathrm{mg} / \mathrm{L}), 7$ (26.92\%) patients whose plasma levels were above therapeutic range did not manifest any features of toxicity. It again highlights the need of individualized/ personalized therapy. Another patient in whom toxicity was manifested as dizziness and sedation, also complained of increased appetite and weight gain. Metabolic concern is rarely seen with Carbamazepine [6]. It may, therefore, be attributed to Valproate co-prescription.

Isoniazid, cimetidine, and erythromycin (CYP3A4 inhibitors) may cause carbamazepine to accumulate [24]. Four cases of co-prescription with $\mathrm{CYP}_{3} \mathrm{~A}_{4}$ inhibitor (valproate in all cases) have been reported [25]. In two of them, plasma levels were respectively 13.6 and $12.36 \mathrm{mg} / \mathrm{L}$. However, no clinical features of toxicity were appreciated in them. In the other two cases, plasma levels were respectively, $8.49 \mathrm{mg} / \mathrm{L}$ and $3.62 \mathrm{mg} / \mathrm{L}$. In another patient with phenytoin (enzyme-inducer) co-prescription, carbamazepine plasma level was, paradoxically, high $(15.96 \mathrm{mg} / \mathrm{L})$ without any features of toxicity.

Our study has some limitations. Firstly, we did not measure another major metabolite- carbamazepine-10,11-epoxide, an important confounder. Secondly, two patients were freshly started on carbamazepine for less than 2 weeks. Plasma drug levels during the first few weeks may be low due to auto-induction [26, 27]. Thirdly, we also did not take a history of caffeine intake which could diminish the efficacy of carbamazepine [28].

\section{CONCLUSION}

7 lasma carbamazepine levels [median (IQR] were determined as $10.01(6.27,13.35) \mathrm{mg} / \mathrm{L}$ and 10.53 $(5.17,15.19) \mathrm{mg} / \mathrm{L}$ in pediatric and psychiatry patients respectively. Plasma level of carbamazepine was therapeutic in $50 \%$, subtherapeutic in $11.54 \%$, and above therapeutic in $36.46 \%$ patients. There was no significant correlation between the dose and plasma level of carbamazepine. Therapeutic drug monitoring of carbamazepine should be done only when non-compliance or toxicity is suspected. 


\section{References}

I. Schmidt S, Schmitz-Buhl M. Signs and symptoms of carbamazepine overdose. J Neurol. 1995;242(3):I69-73. DOI: I0.I007/ BF0093689।

2. Rwiza HT, Keyser A, Hekster YA, Pool M,Verwey H. Retrospective analysis of drug treatment in epileptic patients. Pharm Weekbl Sci. I989; I I (2):50-5. DOI: I0. I007/BF0 962975

3. Stogmann W. Epileptische Anfallsleiden im Kindesalter: Klassifizierung, Diagnose, Therapie [Epileptic seizures in childhood: classification, diagnosis, therapy]. Padiatr Padol. 1986;2I(3):303-I6. German. PMID: 309577I.

4. Elphick M, Yang JD, Cowen PJ. Effects of carbamazepine on dopamine- and serotonin-mediated neuroendocrine responses. Arch Gen Psychiatry. 1990;47(2):135-40. DOI: 10.1001/archpsyc.1990.01810140035006 ר

5. Warren JW Jr, Benmaman JD, Wannamaker BB, Levy RH. Kinetics of a carbamazepine-ethosuximide interaction. Clin Pharmacol Ther. 1980;28(5):646-5I. DOI: 10.1038/clpt.1980.216

6. Ketter TA, Haupt DW. Perceptions of weight gain and bipolar pharmacotherapy: results of a 2005 survey of physicians in clinical practice. Curr Med Res Opin. 2006;22(I2):2345-53. DOI: I0.II85/030079906XI486I6

7. livanainen M. Phenytoin: effective but insidious therapy for epilepsy in people with intellectual disability. J Intellect Disabil Res. I998;42 Suppl I:24-3I. PMID: I0030428.

8. May DC. Acute carbamazepine intoxication: clinical spectrum and management. South Med J. 1984;77(I):24-6. DOI: 10.1097/000076 I |-198401000-00008

9. Barre J, Didey F, Delion F, Tillement JP. Problems in therapeutic drug monitoring: free drug level monitoring. Ther Drug Monit. | 988; I0(2): I 33-43. DOI: I0.1097/0000769|-198802000-00002

10. Levy RH, Yerby MS. Effects of pregnancy on antiepileptic drug utilization. Epilepsia. 1985;26 SuppI I:S52-7. DOI: I0. I I I /j. I528I I57.1985.tb05724.x

II. Rosner B. Fundamental of Biostatistics. 7th ed. Brooks/Cole, Cengage Learning; 2020. DOI: https://doi.org//0.1080/10543406.20। I.592364

12. Bertilsson L. Clinical pharmacokinetics of carbamazepine. Clin Pharmacokinet. I978;3(2):I28-43. DOI: I0.2I65/00003088197803020-00003

13. Chbili C, Hassine A, Laouani A,Amor SB, Nouira M,Ammou SB, et al. The relationship between pharmacokinetic parameters of carbamazepine and therapeutic response in epileptic patients. Arch Med Sci. 20 I 7; I 3(2):353-60. DOI: I0.5 I |4/aoms.20 I6.60090

14. Nolen WA, Jansen GS, Broekman M. Measuring plasma levels of carbamazepine.A pharmacokinetic study in patients with affective disorders. Pharmacopsychiatry. I988;2 I (5):252-4. DOI: I0.1055/s2007-1016965

I5. Shakya G, Malla S, Shakya KN, Shrestha R. Therapeutic drug monitoring of antiepileptic drugs. JNMA J Nepal Med Assoc. 2008;47(I 7| ):94-7. DOI: https://doi.org//0.3 I729/jnma.294

16. Tomson T, Lindbom U, Ekqvist B, Sundqvist A. Epilepsy and pregnancy: a prospective study of seizure control in relation to free and total plasma concentrations of carbamazepine and phenytoin. Epilepsia. I994;35(I):I22-30. DOI: I0. I I I I/j.I528-I I57.I994. tb0292I.x

17. Semah F, Gimenez F, Longer E, Laplane D, Thuillier A, Baulac M. Carbamazepine and its epoxide: an open study of efficacy and side effects after carbamazepine dose increment in refractory partial epilepsy. Ther Drug Monit. 1994;16(6):537-40. DOI: 10.1097/0000769|-1994/2000-0000|

18. Riva R,Albani F,Ambrosetto G, Contin M, Cortelli P, Perucca E, et al. Diurnal fluctuations in free and total steady-state plasma levels of carbamazepine and correlation with intermittent side effects. Epilepsia. 1984;25(4):476-8I. DOI: I0.II I I/j.I528-II57.1984. tb03446.x
19. Miyakoshi M. Aging variabilities of level-dose relationship in antiepileptic monopharmacy- with reference to drug interaction between mono- and bipharmacy. Jpn J Psychiatry Neurol. 1986;40(3):329-35. DOI: I0.I I I I/j.|440-1819.1986.tb03 I55.x

20. Czochańska J, Losiowski Z, Prokopczyk J, Zimak J. Dawkowanie karbamazepiny a jej poziom w surowicy krwi u dzieci [Carbamazepine dosage and its blood serum level in children]. Neurol Neurochir Pol. 1987;2I (I):6-I0. Polish. PMID: 36I 4524.

21. Porter RJ. How to initiate and maintain carbamazepine therapy in children and adults. Epilepsia. 1987;28 Suppl 3:S59-63. DOI: I0. I I I/j. I528-I I57.1987.tb05779.x

22. Tomson T, Tybring G, Bertilsson L, Ekbom K, Rane A. Carbamazepine therapy in trigeminal neuralgia: clinical effects in relation to plasma concentration.Arch Neurol. 1980;37(I I):699-703. DOI: 10.100 I/archneur. I 980.00500600047009

23. Brunton L, Chabner B, Knollman B. Goodman and Gilman's The Pharmacological Basis of Therapeutics. I2th ed. Mcgraw-Hill; 2010.

24. Kutt $\mathrm{H}$. Interactions between anticonvulsants and other commonly prescribed drugs. Epilepsia. 1984;25 Suppl 2:S I I8-3 I. DOI: | 0. I | | |/j. I528- I |57.|984.tb05644.x

25. Ding J, Wang Y, Lin W, Wang C, Zhao L, Li X, et al. A population pharmacokinetic model of valproic acid in pediatric patients with epilepsy: a non-linear pharmacokinetic model based on protein-binding saturation. Clin Pharmacokinet. 20I5;54(3):305-I7. DOI: 10.1007/s40262-014-02 I2-8

26. Pynnonen S, Sillanpaa M, Frey H, lisalo E. Carbamazepine and its I0, II-epoxide in children and adults with epilepsy. Eur J Clin Pharmacol. I 977 Jan 3; I I (2): I 29-33. DOI: I0. I007/BF00562904

27. Kanarkowski R, Wankiewicz G, Lehmann W, Rybakowski J. Pharmacokinetics of carbamazepine in psychiatric patients. Pol J Pharmacol Pharm. 1988;40(I):55-6I. PMID: 3237559.

28. Czuczwar SJ, Gasior M, Janusz W, Szczepanik B, Włodarczyk D, Kleinrok Z. Influence of different methylxanthines on the anticonvulsant action of common antiepileptic drugs in mice. Epilepsia. | 990;3 | (3):3 |8-23. DOI: |0.| | | |/j.| 528-I| 57.|990.tb05382.x 